This is a preprint of a paper whose final and definitive form will be published in Biology and Philosophy.

\title{
Dehorning the Darwinian Dilemma for Normative Realism
}

\author{
Michael J. Deem \\ Department of Multidisciplinary Studies and The Center for Genomic Advocacy \\ Indiana State University \\ http://mjdeem.weebly.com \\ michael.deem@indstate.edu
}

\section{Introduction}

Several philosophers have argued that considerations of the evolution of human evaluative experience problematize versions of normative realism committed to the existence of normative truths that are independent of human evaluative attitudes (e.g., Fraser 2014; Joyce 2006; Ruse 1986; Street 2006). These arguments purport to show that explanation of our evaluative experience does not require positing an irreducible normative reality, and so an acceptable account of the truth or justification of our normative beliefs cannot be construed along realist lines. While there has been no shortage of realist rejoinders to the epistemological elements of this challenge, an important dimension of the debate has been overlooked. Street (2006) claims that the normative realist cannot provide a scientifically acceptable account of the relation between, on the one hand, the evolutionary forces that shaped our evaluative attitudes and, on the other, the stance-independent normative facts the realist posits. ${ }^{1}$ Her unique scientific challenge couples the explanatory challenge typical of evolutionary debunking arguments with a specific set of scientific methodological criteria, which Street claims cannot be satisfied by normative realism. In this paper, I address this neglected aspect of Street's argument.

\footnotetext{
${ }^{1}$ By stance-independent I mean independent of any hypothetical or actual psychological attitude. I adopt Street's use of the term, which follows Shafer-Landau (2003).
} 
I begin by clarifying Street's argument and showing that her preferred evolutionary account of evaluative judgment, the Adaptive Link Account, fails to satisfy two of the three scientific criteria she employs in her critique of normative realism, namely clarity with respect to why these judgments were adaptive and illumination of the explanandum. I then argue that a byproduct view of evaluative judgment can serve as a plausible alternative to the adaptationist approach that dominates the evolutionary debunking literature. A byproduct view, I suggest, can be adopted by the realist as one way to meet the scientific challenge. Finally, I argue that, from a biological point of view, considerations of ontological parsimony, Street's third criterion, do not weigh significantly against the conjunction of this byproduct account and normative realism.

Before proceeding, I wish to register two caveats. First, I share Fraser's (2014) concern that the debunking debates in ethics have largely neglected the scientific and empirical details pertinent to an inquiry into the evolutionary origins of evaluative judgment. Accordingly, much of my discussion involves foregrounding and clarifying the relevant scientific concepts and methods that typically receive little attention in these debates. This leads to a second caveat: I will not attempt to develop a substantive evolutionary account on the realist's behalf. My more modest intention here is to outline and defend a plausible evolutionary perspective that is congenial to both nonreductive naturalist and nonnaturalist brands of normative realism.

\section{The Darwinian dilemma}

Street's evolutionary argument against normative realism takes the form of a dilemma generated by the realist's acceptance of the following hypothesis:

EVOLUTIONARY HyPOTHESIS: Natural selection played a significant role in shaping our evaluative tendencies, thereby influencing the content of our most basic evaluative judgments. 
By evaluative tendency, Street means "an unreflective, non-linguistic, motivational tendency" to behave in a particular way $(2006,119)$. By our most basic evaluative judgments (hereafter 'basic evaluative judgment'), Street denotes evaluative judgments that enjoy widespread affirmation across time and cultures and happen to be endorsements of evolved evaluative tendencies (ibid., $115-117,158 \mathrm{n} 15)$.

The realist needs to explain what, if any, relation obtained between selective pressures on evaluative judgment and the normative facts realism posits. Herein lies an alleged 'Darwinian dilemma' (DD). Suppose the realist were to deny a relation obtained between the two. This would lead to skeptical worries that selective pressures shaped evaluative judgments in ways quite unrelated to normative facts. Alternatively, the realist might contend that some relation obtained between the two. Street suggests that the most plausible way for the realist to construe this relation is as one of truth-tracking along the following lines:

Tracking ACCOUnT (TA): Human make certain basic evaluative judgments rather than others because these judgments are (i) true and (ii) making true evaluative judgments was adaptive for our ancestors.

Street proposes her own Adaptive Link Account as a rival to TA:

AdAPTIVE LinK ACCOUNT (ALA): Humans make certain basic evaluative judgments rather than others because these judgments forged adaptive links between our ancestors' behavior and the environment(s) in which they lived.

On ALA, some evaluative judgments enabled our ancestors to "act, feel, and believe in ways that turned out to be reproductively advantageous" (ibid., 127) such that tendencies to make these judgments were favored by selection.

ALA, Street contends, is the superior explanation on three methodological criteria (ibid., 129-34): (i) it is more illuminative of the explanandum; (ii) it provides a clearer answer to the question of why basic evaluative judgments were adaptive for our ancestors; and (iii) it is more 
parsimonious insofar as it omits reference to independent normative facts. By these criteria, Street concludes, TA is "unacceptable on scientific grounds" (ibid., 109). Thus, by affirming a relation obtained between selection and normative facts, the normative realist faces what I am calling Street's scientific challenge.

How might the realist respond to the scientific challenge? In the next section, I argue that ALA fails to deliver the clear and illuminating explanation of our basic evaluative judgments promised by Street. From there, it remains for the realist to adopt a workable strategy for developing a plausible evolutionary account of evaluative judgment. I will outline and defend one such strategy in the sections that follow.

\section{Problems for ALA}

The central claim of ALA is that basic evaluative judgments are "deeply analogous" to hard-wired mechanisms we observe in other animals and plants, such as the Venus flytrap's reflex mechanism for capturing prey or animal responses to pain stimuli (ibid., 127). According to Street, evaluative judgments play a functional role analogous to such mechanisms in that they forged an adaptive fit between organism and environment (ibid., 128). Just as selection favored and fixed certain traits in populations of plants and animals because these traits provided an adaptive advantage, selection favored certain kinds of basic evaluative judgments because they

provided an adaptive advantage to those of our ancestors who tended to make them. Thus, ALA is clearly committed to an adaptationist view of basic evaluative judgments. While ALA might appear to provide a plausible explanation for basic evaluative judgments, closer scrutiny reveals the account to be implausible on both theoretical and empirical grounds. 


\section{ALA is intuitively implausible}

One might initially wonder whether ALA aims to explain basic evaluative judgments themselves or the general tendency to make such judgments. Taking Street's unpacking of ALA at face value, we can rule out the latter. This is because Street excludes from ALA's purview the two candidate traits that 'tendency' might denote. On the one hand, one might think this tendency is explained in terms of the evaluative tendencies Street mentions. But ALA is an account of basic evaluative judgments, which are distinct from the phylogenetically ancient tendencies that may influence their content. ALA clearly ascribes an evolutionary function to basic evaluative judgments and omits any reference to the evolutionary function of the phylogenetically distinct evaluative tendencies. Moreover, evaluative tendencies do not themselves explain why humans make an additional judgment or endorsement of an evaluative tendency. On the other hand, one might think this tendency is some phylogenetically novel capacity for evaluative judgment. But Street expressly states that she does not intend ALA to be an explanation of the capacity to make evaluative judgments (ibid: 160n32). So, accepting ALA at face value, certain basic evaluative judgments are the adaptation to be explained.

Now, adaptations are heritable traits that generated outcomes that contributed to the survival and reproductive success of individuals during the course of the evolutionary history of a population. In ascribing to basic evaluative judgments an evolutionary function, ALA characterizes evaluative judgment as one such process. Now consider that a trait is a biological adaptation only if it is heritable. This means that if basic evaluative judgments are adaptations (and therefore have evolutionary functions), as ALA holds, then basic evaluative judgments must be heritable. However, Street acknowledges that evaluative judgments are not heritable (ibid., 
118-119). But if no evaluative judgment is heritable, then basic evaluative judgments are not adaptations and do not, therefore, have an evolutionary function. This contradicts ALA.

Suppose we were to try to diffuse this problem by noting that Street holds that selection only favored basic evaluative judgments indirectly. This won't do. If evaluative judgments were indirectly selected for, then they do not, strictly speaking, have a biological function, since a biological function is the purpose for which a trait was (directly) favored by selection. If they do not have a biological function, then they are not an adaptation. Again, we reach a contradiction. Therefore, Street's function analogy, which is the heart of ALA, does little to illuminate the evolutionary origins of basic evaluative judgments.

Even if we were to modify ALA slightly by taking the explanandum to be the capacity to make basic evaluative judgments, difficulties persist. Street holds that the capacity for evaluative judgment was a "relatively late add evolutionary add on," distinct from evolved evaluative tendencies already fixed in humans (ibid., 117). Like any evolutionary innovation in cognitive machinery, the capacity for evaluative judgment has biological maintenance cost, so if this specific capacity is an adaptation, it must have yielded a sufficiently high fitness payoff for individuals to offset that cost. With this in mind, perhaps considering an ideal case will help us determine whether this picture is clear.

Imagine an ancestral hominid population $\mathrm{P}$ containing two subpopulations, one containing individuals who posses the capacity for making these evaluative judgments $\left(\mathrm{S}_{1}\right)$ and the other containing individuals $\left(\mathrm{S}_{2}\right)$ who do not. If ALA is correct, there must have been significant selective pressures in the direction of preserving the capacity for making these judgments such that $\mathrm{S}_{1}$ swamped $\mathrm{S}_{2}$, eventually wholly constituting $\mathrm{P}$. Now, if the basic evaluative judgments $S_{1}$ made were simply endorsements of evolved evaluative tendencies that 
they share with $S_{2}$, then there is a striking redundancy in $S_{1}$ 's evaluative system, since presumably behavioral outcomes connected with the making of evaluative judgments by $\mathrm{S}_{1}$ would not vary much or at all with the behavior of $\mathrm{S}_{2}$. But a redundancy whose enabling mechanisms needlessly squander energy or resources is likely to be selected against. Moreover, consider Street's observation that many of our evaluative judgments can "stray, perhaps quite far" from our inherited evaluative tendencies, and that our capacity for evaluative judgment includes the ability to "disavow" and "fight against" our evaluative tendencies (ibid., p. 120). Given that possibility, it is difficult to imagine that this capacity would have been more reliable at producing the same fitness-enhancing behaviors as the evolved evaluative tendencies if, in fact, basic evaluative judgments just are reflective endorsements of such tendencies. It seems, therefore, that the capacity to make evaluative judgments would not have been a cost-effective way of getting our ancestors to behave adaptively, assuming that the content of basic evaluative judgments is primarily determined by evolved evaluative tendencies. Street owes us, then, an account of how making these evaluative judgments contributed to the fitness of our ancestors over and above the evaluative tendencies that would have generated similar behavioral outcomes.

One way Street might respond to this objection would to be argue that while evaluative judgments are not redundant mechanisms, they are functionally redundant to evaluative tendencies; perhaps evaluative judgments were selected for because they reinforce the behaviors for which our basic evaluative tendencies call. Perhaps increasingly complex social arrangements among our ancestors created more opportunities and temptation for individual defection, and basic evaluative judgments evolved to reinforce the kinds of cooperative behavior that secured fitness benefits for individuals, maybe even for the group. After all, a widely held view among 
normative realists and anti-realists alike is that evaluative judgment provides some additional motivational push beyond mere evaluative or motivational tendencies.

While this response might initially appear promising, it leaves too much unexplained. Simply pointing to the fact that evaluative judgment provides an additional push toward a certain kind of behavior only identifies a trait amenable to an evolutionary explanation. It does not explain why selection targeted judging that certain actions or states of affairs are 'wrong' or 'good' was a more reliable way for motivating cooperative behavior than the deeply rooted tendencies selective forces had already shaped to produce similar adaptive behavior. ${ }^{2}$ Moreover, it is not clear why we should think evolutionary forces would fashion in our ancestors an additional, complex capacity for evaluative judgment rather than just tinker with those motivational and behavioral traits that were already fixed in individuals, including motivational tendencies to punish defectors, which we find present in other primates. This is precisely the explanation that an adaptationist account needs to provide, yet ALA fails to shed light on the matter.

Consider what may be a more plausible evolutionary scenario: if evaluative tendencies became at some point in our evolutionary history unreliable for motivating cooperative behavior, either these tendencies would have been strengthened by further selective pressure or other fixed,

\footnotetext{
${ }^{2}$ Joyce argues that moral judgments express both a belief about a normative standard and a conative acceptance of that standard, the latter of which "denotes a motivation-implicating state" $(2006,109)$. Why is a mental state with propositional content needed in addition to a strong conative state to generate the requisite motivation for the adaptive behavior? Joyce suggests that Robin Dunbar's grooming and gossip hypothesis provides a clue: language to facilitate social cohesion within increasingly large groups through the exchange of information about individual reputations. Joyce suggests that language would have been utilized not only to describe, say, failures of individuals to reciprocate helpful action, but to criticize those individuals. So language may have evolved to evaluate and keep score of others' actions within large groups engaging in complex forms of exchange, much the same way as grooming facilitates social cohesion within small groups of nonhuman primates. While it is not possible to provide an assessment of Joyce's account here, it is worth noting that Dunbar's hypothesis has been challenged on both theoretical and empirical grounds. For example, Bickerton (2009) and Barnard (2012) have argued that the grooming and gossip hypothesis does not explain the complexity of language and the conceptual sophistication required for it, and each contends that language evolved for purposes quite apart from social evaluation and cohesion.
} 
co-present motivational tendencies would have sufficed or been strengthened by natural selection to reinforce that behavior. With respect to the latter possibility, one might think that mutualistic tendencies, which are widely shared by primates and have deeper phylogenetic roots than evaluative judgment, could have sustained cooperative interaction with non-kin within the small bands in which our ancestors lived and evolved. This is not to suggest that evaluative judgment played no role in cooperative activity among early humans, or even that evaluative judgment did not come under selective pressures at some point in human evolutionary history; rather, it is to point out that there is little evidence that evaluative judgment evolved just to call for similar behaviors as fixed evaluative tendencies, or specifically to remedy deficiencies of evaluative tendencies within cooperative contexts. ${ }^{3}$

\section{ALA is untenable on empirical grounds}

At the intuitive level, then, ALA is a rather tenuous explanation of basic evaluative judgments. But we should not rely solely on our intuitions when assessing the plausibility of an evolutionary account. Recall that ALA's central claim is that basic evaluative judgments are "deeply analogous" to hard-wired mechanisms in other species. If this claim were true, we would expect the capacity to make evaluative judgments to be relatively inflexible and cue-bound, or at the very least exhibit these profiles in the early stages of moral and social cognitive development. But the immense body of empirical research on human social learning and moral development indicates that something quite the contrary is the case: evaluative judgment exhibits a high

\footnotetext{
${ }^{3}$ Joyce (2006), handling a similar objection from Lahti (2003), suggests it makes little sense to ask why selection didn't simply strengthen existing motivational tendencies to get us to act in certain ways. He asserts that natural selection did design us to act this way, and evaluative judgment was a way to do it. Joyce frames the question as being about natural selection choosing between two options, namely a desire for a given behavior or a mechanism that facilitates the desire. But the question is about the reliability of evolved evaluative tendencies for cooperative behavior already in place among our ancestors prior to the evolution of evaluative judgment.
} 
degree of flexibility and sensitivity to variation in social learning environments. Here I shall focus on one area of this literature, namely developmental studies of moral judgment and social behavior in humans. Consideration of these studies will suffice to show that ALA's account of basic evaluative judgments is both descriptively inadequate and implausible on empirical grounds.

If ALA is correct in asserting that basic evaluative judgments are analogous to other 'hard-wired' traits, we should expect developmental research to show that the emergence of evaluative judgment in young children either follows a simple, unitary pathway toward correspondence with basic evaluative tendencies, or that evaluative judgment is relatively inflexible at its developmental origin (prior to familial and social influence on norm acceptance). However, several developmental studies have found that neither scenario is the case.

Longitudinal and concurrent studies of moral development in children show that predispositions to experience moral emotions, such as empathy and guilt, and the process and degree of internalization of social and cultural norms is determined in large part by the character of early parental interaction and other relationships of care. For example, through a series of studies Kochanska and colleagues found that children's early acceptance and compliance with familial norms in the early stages of moral development correlates with the degree of maternal affective responsive to child need and distress, and the degree of cooperation within parent-child interactions such as play, eating meals, and household chores (Kochanska 2002; Kochanska \& Murray 2000; Kochanska et al. 2005). These studies suggest that the development of a moral sense in children and of patterns of evaluative judgments across a range of social situations varies significantly according to the degree of mutual responsiveness present in the parent-child dyad. 
Similar findings emerged from Deborah Laible and colleagues' research on the emotional mediation of moral judgment and social behavior. Children who form secure attachment relationships with parents and peers, and frequently conduct emotion-laden conversations about their previous behavior and actions within these relationships, exhibit an increased capacity to cultivate emotional understanding and internalize social and moral norms (Laible 2007; Laible \& Thompson 2000). Laible and colleagues suggest that patterns of evaluative judgment among children and adolescents are sensitive to familial and social contexts, and are more directly influenced by the development of dispositions to experience social emotions like guilt and empathy. Their work shows not only that evaluative judgment is malleable in young children, but also that development of emotional dispositions, which might be counted as evaluative tendencies, exhibit wide variability depending on the kind and quality of children's attachment relationships. Additional studies of children's ability to identify and respond to others' harming and helping behavior suggest that children as young as two years of age are capable of rudimentary moral judgments that are dissociated from other evolved dispositions and capacities that underwrite social behavior, including elicitors of stress and perceptions of distress in others (Hamlin 2012; Vaish et al. 2009; 2010).

Cross-cultural research on how children and adults weigh particular moral duties, and the degree to which they privilege interpersonal or impersonal values within practical deliberation, shows that patterns of evaluative judgment in both groups vary across cultural contexts. For example, Miller and Bersoff (1992) and Miller (1994) found that this variation is not associated with differences among subjects' perceptions of the seriousness of certain moral contexts (e.g., breaches of moral norms), nor does it vary along the lines of a putative distinction between conventional and moral norms. The cultural patterning of evaluative judgment suggests a much 
looser association between what might be universal or widespread evaluative tendencies and the kinds of evaluative judgments humans make than that which ALA supposes, with cultural influence often playing a significant role in shaping the content of these judgments.

Developmental and cross-cultural research on moral development in children, therefore, undermines ALA's claim that basic evaluative judgments are analogous to evolved, hard-wired mechanisms in other species. Far from aligning with phylogenetically widespread evaluative tendencies, patterns of human evaluative judgments show significant variation according to the familial and cultural contexts in which moral development occurs. This includes patterns of evaluative judgments that Street alleges are explainable by reference to kin selection and reciprocal altruism, such as evaluative judgments about appropriate responses to the needs of close relatives, the reciprocation of helpful behaviors performed by non-kin, and navigating intergroup relations (Bartels 2008; Heisphetz \& Young 2014; Thompson et al. 2003). During moral and social development, the emerging capacity in children to form basic evaluative judgments does not inflexibly correspond to fixed emotional or behavioral tendencies, but instead exhibits a keen sensitivity to variations within and across social contexts. This is not to suggest that evolved evaluative tendencies play no role in shaping patterns of these judgments, but it is to suggest that the determination of these patterns is multifactorial, jointly formed by a range of ontogenetic inputs as well as evolutionary factors.

\section{Taking stock}

ALA, thus, is fraught with theoretical difficulties, and its claim that basic evaluative judgments are analogous to hard-wired evolutionary traits stands at odds with current empirical 
research on moral and social development in humans. ${ }^{4}$ Furthermore, it leaves us without a clear picture of the link between basic evaluative judgments and the ancestral environment in which they evolved. In asserting that basic evaluative judgments are adaptations without also providing a clear account of their evolutionary origin, ALA does little to explain the widespread patterns of evaluative judgments among humans, and so fails to satisfy two of the three desiderata Street privileges, namely illumination of the explanandum in question and clarity with respect to why these judgments were adaptive and favored by selection.

While the foregoing considerations reveal the inadequacies of ALA, it still remains to be seen whether normative realism is compatible with the EVOLUTIONARY HYPOTHESIS. To show that they are, indeed, compatible, I turn now to sketching an alternative evolutionary perspective on basic evaluative judgments, which the normative realist can adopt.

\section{An evolutionary alternative for the normative realist}

ALA and TA are adaptationist approaches to the explanation of basic evaluative judgments. For such adaptationist explanations to work, they must account for the evolutionary emergence and maintenance of the capacity for evaluatively judging and not simply for the more phylogenetically widespread evaluative tendencies that may influence the content of some of our basic evaluative judgments. If evaluative judgment is more phylogenetically recent than these

\footnotetext{
${ }^{4}$ ALA appears also to stand in tension with dual process models of social cognition (DPMs), which are prevalent in the social and cognitive psychology literature. DPMs generally distinguish between two levels of cognitive processes that jointly underwrite human behavioral, social, and moral judgments. On one level are cognitive processes marked by speed, unregulated automaticity, and efficiency with respect to the formation of mental representations of, and behavioral motivation in response to, environmental stimuli. Commonly grouped among these processes, which are often dubbed 'System 1' (S1) processes, are emotional regulation, attention biases, behavior contagion, and threat and reward sensitivity. According to DPMs, S1 processes are contrasted with 'System 2' (S2) processes, which are slow, reflective, and selective with respect to execution. DPM theorists often take S1 processes to be evolutionary old and phylogenetically widespread, and S2 processes to be evolutionarily new and perhaps unique to the hominin lineage. While Street's characterization of evaluative tendencies would appear to place them at the $\mathrm{S} 1$ level, her view of basic evaluative judgments as reflective endorsements of such tendencies would seem to place them at the S2 level. If that is correct, then basic evaluative judgments would hardly resemble hard-wired processes, but instead would look more like regulated, selective S2 interventions.
} 
evaluative tendencies, the latter of which have an independent evolutionary history tied to the behaviors they promoted, then we must explain why the additional capacity for evaluative judgment came under selective pressure. Given the challenges ALA and TA face, perhaps it is worth considering how shifting from an adaptationist perspective on evaluative judgment to an evolutionary byproduct perspective might fare.

\section{A byproduct framework for evaluative judgment}

On a byproduct account, the capacity for evaluative judgment is an effect of cognitive mechanisms that were fashioned by natural selection. By 'effect' I mean a trait that was not targeted by natural selection to serve its current role. ${ }^{5}$ A byproduct view of evaluative judgment holds that the underlying cognitive mechanisms responsible for evaluative judgment were the target of selective pressures on account of their governing other adaptive processes and behaviors in our evolutionary past. A byproduct perspective thus does not join ALA and TA in assuming that evaluative judgment is an adaptation, though it does offer an evolutionary perspective on the trait in question by pointing to the enabling adaptations that incidentally gave rise to it. ${ }^{6}$

Before proceeding to sketch the framework of a byproduct perspective on evaluative judgment, let me forestall a potential worry that adopting this framework would simply be an ad

\footnotetext{
${ }^{5}$ It is worth noting that the claim that a given trait is not an adaptation does not entail the view that the trait was never adaptive. While an effect was not the target of selective pressures, it could have been co-opted after its emergence to play some adaptive role at a later evolutionary stage of a population (Gould \& Vrba 1982; Gould 1991).

${ }^{6}$ Street briefly considers the byproduct option before summarily dismissing it as implausible: "It is completely implausible, for instance, to suggest that the human eye in its present developed form emerged as the purely incidental byproduct of selection for some other, unrelated capacity. I suggest that it is no more implausible to claim that the sophisticated ability to grasp independent evaluative truths emerged as such a byproduct" $(2006,143)$. Street's dismissal not only ignores byproduct accounts of many sophisticated cognitive traits (e.g., Atran 2010; De Smedt \& De Cruz 2010; Piattelli-Palmarini 1989), but also plainly begs the question against a byproduct account of evaluative judgment by comparing the evolutionary processes that brought about the capacity for evaluative judgment to those that brought about the human eye.
} 
hoc maneuver designed to avoid the problems adaptationist explanations pose for normative realism. Byproduct accounts of evaluative judgment are not novel in the philosophical literature, and they have enjoyed endorsement by philosophers who do not espouse the kinds of normative realism on which evolutionary debunking arguments focus (e.g., Nichols 2002; Prinz 2009; Ayala 2009). These philosophers find byproduct accounts of evaluative judgment to be plausible apart from any specific metaethical commitment.

Some philosophers who are sympathetic to normative realism have recently expressed support for a byproduct account. For example, De Lazari-Radek \& Singer suggest that once selection favored a general capacity for reasoning within our ancestral populations, humans may have become "unable to avoid recognizing and discovering some truths that do not aid our survival," including normative truths $(2014,182)$. In a similar vein, FitzPatrick contends that if selection has "given us general cognitive capacities that we can now develop and deploy in rich cultural contexts, with training in relevant methodologies," then an adaptationist account along the lines of TA may not be required to show that normative realism is compatible with evolutionary theory $(2015,887)$.

A byproduct perspective, thus, seems compatible with an array of metaethical commitments. It is one thing to commend or endorse a byproduct account, however, and quite another to show both that there are adequate reasons for preferring it to an adaptationist alternative and that a realist's byproduct account could meet Street's scientific challenge. Very little work has been done in this regard, and in the remainder of this section and the next, I begin that task. 
The grasping capacity view

Because an evolutionary perspective presupposes the presence of the focal trait, the kind of byproduct account that the normative realist utilizes would be shaped having in mind realism's commitment to irreducible normative truths. As a rough and very broad construal of this perspective—congenial to both non-reductive naturalist and non-naturalist metaethical positions-I propose the following:

GraSPING CAPACITY VIEW (GCV): Human beings grasp stance-independent normative truths because the cognitive mechanisms necessary to do so were adaptive.

According to GCV, humans evolved the necessary cognitive capacities to grasp normative truths, but, as a byproduct account, GCV maintains (in contrast to TA) that grasping normative truths and making true evaluative judgments are not the functions of these capacities. Rather, evaluative judgment is taken to be an incidental effect of other enabling faculties that were selected to perform specific biological functions that contributed to the survival and reproductive success of our ancestors.

Now, a full-scale defense of GCV would require evolutionary explanations and descriptively adequate accounts of the enabling cognitive capacities - mammoth undertakings well beyond the scope of this paper. While my intention here is only to sketch the contours of GCV and address the question of whether the realist can meet Street's scientific challenge by adopting it, a few words should still be said about how these enabling capacities might lead to the discovery of irreducible normative truths. For GCV to be plausible, the cognitive faculties responsible for evaluative judgment must be such that they do not evidently require an additional evolutionary explanation to account for the capacity to make evaluative judgments, some of which turn out to be true. So we might first ask whether we have reason to think that the cognitive faculties that likely were shaped by natural selection for functions other than making 
evaluative judgments would be sensitive to the normative truths the realist posits. Here, nonnaturalism tends to engender greater controversy than non-reductive naturalism, so I will focus for the moment on the former.

It might be tempting to think that, if there are nonnatural normative truths, a special cognitive faculty is necessary to grasp them. But the ontological commitments of nonnaturalism do not entail that a sui generis faculty must be available for grasping them. Indeed, the most plausible versions of nonnaturalism abstain from positing a unique or obscure cognitive faculty that enables us to grasp normative facts (e.g., Stratton-Lake 2002; Roeser 2011). These versions of nonnaturalism require no more than a faculty capable of grasping the conceptual truth of certain normative propositions - a faculty that need be no more exotic than that which grasps the truth of general and abstract propositions, such as those of mathematics and logic. So the pertinent question is whether the nonnaturalist could make good on the claim that the cognitive faculties that underlie evaluative judgment have plausible selectionist stories.

Which cognitive capacities would the nonnaturalist claim enable the grasping of normative truths? Presumably, these would include the ability to discriminate, abstract from, and classify persons, events, and actions, the ability to anticipate and predict consequences of one's own behavior and that of one's conspecifics, and the capacity for belief formation. Two recent theories of the evolutionary development of these faculties in humans are especially helpful in thinking about the possible evolutionary pathways to evaluative judgment. Godfrey-Smith (1996) argues that the evolutionary function of complex cognitive faculties is to enable an organism to deal with complex environments. Cognitive complexity enables an organism to adjust and react adaptively to ecological variability. Sterelny (2003) contends that populations within heterogeneous and informationally opaque environments would undergo selective 
pressure for capacities to decouple representational states from the cue-bound behavior characteristic of simpler detection systems suitable for transparent environments. The demand for complex representational systems would be especially keen in the context of complex primate social environments (Kummer et al. 1997; Sterelny 2012). Whether one focuses on environmental complexity or informational opacity, the enabling conditions of evaluative judgment may be explainable in terms of the cognitive demands of primate social life and the eventual evolution of cultural scaffolding for intergenerational information transmission. In order to handle and adaptively utilize the informational load of increasingly complex social exchange and cross-generational cultural learning, humans evolved capacities to reason modally, logically, and mathematically. These capacities may have enabled not only the grasping of the conceptual truths of mathematical and logical propositions, but also conceptual truths of normative propositions.

For this to be a plausible view, of course, the way in which humans grasp the conceptual truth of normative propositions must be similar to that by which they grasp the conceptual truth of abstract propositions in domains where judgments were important to production of adaptive behavior. It seems that only then could the realist plausibly maintain that evolution shaped in humans capacities sensitive to irreducibly normative truths. This consideration might force us to acknowledge a dividing line between two families of nonnaturalism with respect to which versions of nonnaturalism are plausible from an evolutionary standpoint. According to 'relaxed' views of nonnaturalism, a commitment to irreducible normative truths does not entail a particular ontological commitment to a realm of nonnatural properties within the world. ${ }^{7}$ The way in which we grasp conceptual normative truths is the same as, or quite similar to, the way in which we grasp the conceptual truths of propositions of the formal sciences. Relaxed versions of

\footnotetext{
${ }^{7}$ I take the label and category of 'relaxed realist' from Cuneo \& Shafer-Landau (2014) and McGrath (2014).
} 
nonnaturalism can be contrasted with their "robust" counterparts, which do posit an independent realm of irreducibly normative facts that serve as the truthmakers of (some) normative propositions (e.g., Enoch 2011; FitzPatrick 2008). GCV might accommodate either family of nonnaturalism, though it is clear that robust versions of nonnaturalism require a considerably more complex evolutionary story than I have provided, one that also explains how human cognitive faculties developed a sensitivity to these independent, nonnatural facts. This may suggest that relaxed versions of nonnaturalism enjoy a higher degree of plausibility than robust versions from an evolutionary perspective, since the former do not require cognitive sensitivity to sui generis features of the world. At any rate, my purpose here is not to vindicate a particular brand of normative realism, but only to show that at least some versions of nonnaturalism - as well as nonreductive naturalism — fit within an evolutionary byproduct framework.

Another important feature of GCV to note is its ability to accommodate the evidence that the content of some of our basic evaluative judgments is susceptible to evolutionary explanation. However, because GCV denies that selection pressures pushed our ancestors to make these judgments, thereby fixing to a large degree patterns of basic evaluative judgment, it leaves room for non-selectionist explanations for the content of other basic evaluative judgments that do not have a straightforward evolutionary explanation. For example, consider the basic evaluative judgment that one has a duty of beneficence that extends beyond kith and kin, a notoriously thorny case for individual-level adaptationist stories. A variety of selectionist accounts for putative duties, such as the duty of beneficence, have been offered by philosophers, ${ }^{8}$ yet these

\footnotetext{
${ }^{8}$ Joyce (2006) and James (2011) appeal to kin selection to explain initial tendencies in early humans for directing helping behaviors toward non-kin, and they suggest that such tendencies underlie further evolved dispositions for cooperation. James suggests that there would not have been selective pressures for fine-grained kin-detection devices, since early humans would have lived in tightly knit communities consisting largely of individuals related to various degrees, who consequently would have been disposed to cooperate to some degree. Following Joyce, James utilizes this kin selection hypothesis to work up to a more complex explanation of a psychological tendency in early humans to cooperate with those living in close proximity, with 'false positives' sometimes prompting the
} 
accounts have been met with skeptical responses by biologists and philosophers who doubt the accounts are sufficiently powerful to explain basic evaluative judgments about duties that extend beyond kin and close associates (e.g., Rosenberg 1990, Silk 2003, Silk and Boyd 2010, Laland and Brown 2011). Here, the realist claims to have something to offer: we tend to make the judgment that we have a duty of beneficence even to strangers because we have grasped some truth about the rightness of beneficent actions. Whether this answer is provided in nonnaturalist or nonreductive naturalist terms, the realist can utilize GCV to help explain why there are some basic evaluative judgments whose contents are not easily accounted for by selectionist models. Moreover, the realist can still accept that the content of other basic evaluative judgments, such as 'that $\Phi$-ing would benefit a close relative is a reason to $\Phi$ ', can largely be explained in nonrealist, evolutionary terms; the realist need not hold that all basic evaluative judgments answer to an independent normative reality, but only that some such judgments are. Thus, a proponent of GCV can consistently affirm the EVOLUTIONARY HYPOTHESIS by adopting an evolutionary perspective on the origin of the underlying mechanisms of the capacity for evaluative judgment and, optionally, a selectionist picture of the content of some of our basic evaluative judgments. Now, the foregoing sketch of GCV does not approach a substantive evolutionary account of evaluative judgment, nor does it venture to address longstanding epistemic, metaphysical, and

cooperation with non-kin. For their accounts to work, a surprising number of major trait transitions would have had to occur in early hominid populations within an improbably short evolutionary timeframe after the spit from their common ancestor with chimpanzees and bonobos: (i) loss of olfactory sensitivity to close kin; (ii) loss of capacity for finer-grained kin detection based on phenotypic clues, a trait that extant primates still possess and, presumably, so too did the last common ancestor before the Pan-Homo split (Parr \& De Waal 1999; Silk 2005; Widdig 2007; Chapais 2010); (iii) a significant change in group composition from primate social groups composed of kin and nonkin to social groups consisting mostly of kin; (iv) despite the evolution of stable breeding bonds and increased biparental care of offspring in early hominid communities, selection would have elaborated the psychological tendencies put in place by kin selection to gradually intensify novel cooperative dispositions toward non-kin. Additionally, according to James, all these rapid transitions likely would have occurred in early humans before the evolution of language. Now, this is not to say that the stories James and Joyce tell are false, but it is to say that their stories appear much less plausible when we take into account probable phylogenetic constraints on kin bias among early hominids and the very short evolutionary time scale on which the trait transitions required for James's and Joyce's stories to work - many of which are phylogenetically novel—would have had to occur. 
motivational debates over the philosophical commitments of normative realism. What is important for my purposes here is the plausibility of GCV's main contentions that evaluative judgment is enabled by other cognitive adaptations, and that these cognitive adaptations are sensitive to the kinds of normative truths that nonreductive naturalist and nonnaturalist realisms posit. Assuming that enough has been said to motivate GCV, we can turn to the question of why a byproduct like GCV would be preferable to an adaptationist account of evaluative judgment.

\section{Deciding between adaptationist and byproduct accounts}

As I alluded to above, a likely concern about GCV is that there needs to be some evidence that favors choosing it over its adaptationist rivals. What sort of evidence could determine whether a given trait is a byproduct or an adaptation? In their classic article on exaptation, Gould and Vrba (1981) note that we should, in principle, be able to discriminate between morphological byproducts and adaptations. In the case of a bird's feathers, for example, Gould and Vrba suggest that the common exaptationist view could be confirmed by the discovery of fossils from a small running dinosaur that had feathers. However, unlike many morphological traits, cognitive faculties and behaviors do not leave behind fossils for the convenience of such confirmation.

In the absence of physical evidence, some scientists and philosophers have proposed other ways for determining whether a trait is an adaptation. Lloyd (2005), for example, suggests the following criteria for determining that a trait is an adaptation: (1) variations of the trait have a genetic basis; (2) the fitness benefits the trait confers can be shown; and (3) we have a clear understanding of the link between the trait and how it helped facilitate evolutionary success. Additionally, Pinker and Bloom (1992) claim (4) a trait's being evidently of complex design is 
evidence in favor of taking that trait to be an adaptation. It is not clear, however, whether these criteria will help to decide the matter with respect to evaluative judgment. Criteria (2) and (3) fail to help in the case of cognitive and behavioral traits since selection pressures on behavioral traits in the past cannot be directly measured in our present environment; the ecological and social conditions in which evaluative judgment evolved have long since passed. With respect to criterion (1), we should acknowledge that, even though evaluative judgment appears to be a fixed trait in humans, there is variation across individuals with respect to both the ability to reason evaluatively and responsiveness to ethically salient features of actions, events, and persons. But whether this phenotypic variability expresses genetic variation across individuals (and not predominantly ontogenetic variation) remains opaque. Thus, it is not clear presently whether (1) is satisfied. Finally, while evaluative judgment is a relatively complex capacity in humans, criterion (4) is too permissive to rule out all byproduct traits, since a high degree of complexity is not sufficient for determining whether a cognitive or behavioral trait is an adaptation (Burian 1983).

Since it is not clear that the common criteria used for determining which traits are adaptations are satisfied, we may have to rely on a methodological point. In contrast to advocates of adaptationist approaches to evaluative judgment, the proponent of GCV contends that it is not necessary to posit an additional cognitive faculty in humans that was selected specifically to make evaluative judgments. While a workable byproduct perspective like GCV does not entail that an adaptationist account must be false, it does shift an argumentative burden to those who wish to provide one for evaluative judgment. ${ }^{9}$

\footnotetext{
${ }^{9}$ Joyce aims to provide reasons in favor of taking moral judgment to be an adaptation as opposed to an evolutionary byproduct (2006, 133-39), but his discussion slips from the question of whether moral judgment is an evolutionary adaptation to whether moral judgment is innate. That a trait is innate does not entail that it is an adaptation.
} 
With these various concerns diffused, we should consider another challenge to versions of normative realism that posit independent normative truths or facts. Suppose the normative antirealist were to retool an account like ALA and tender a plausible evolutionary explanation for widespread patterns of basic evaluative judgments. Since the antirealist's explanation would make no reference to independent normative facts, would it not be a better scientific theory, other things equal, in virtue of being more ontologically parsimonious than any realist rival theory? I now turn to addressing this question.

\section{A parsimony problem?}

While ontological parsimony — in conjunction with other desiderata — is valued across many of the natural sciences, determining which virtues should be exemplified in a particular scientific theory depends largely on the aims of the particular field of science in which the theory is constructed, as well as on the specific features of the problems the theory addresses (Kellert et al. 2006). Within the biological sciences, the importance of parsimony varies according to method and context; for example, it tends to be counted among the desiderata of phylogenetic construction, though not always the most important of virtues (Sober 1990). In other areas of biology, such as biogeography, it serves at most as a sort of "tie-breaker" between rival theories (Baker 2007). What is of concern here is determining what role ontological parsimony might play in choosing among rival evolutionary explanations of evaluative judgment. This requires a consideration of how biologists structure explanations of behavioral traits. 


\section{Four levels of analysis}

The standard structure of an evolutionary-behavioral explanation of a trait comprises four complementary, non-overlapping explanations, or levels of analysis (Tinbergen 1963; Sherman 1988; Bateson \& Gluckman 2011; MacDougall-Shackleton 2011). Each of the four explanatory levels offers a solution to a distinct problem the biologist encounters in the study of a particular behavioral trait: (a) the phylogeny of the trait, (b) the functional consequence of the trait, (c) the ontogenetic processes through which the trait develops in the individual, and (d) the trait's underlying enabling mechanisms. These four solutions combine to form a complex, integrated biological explanation of the behavioral trait being investigated. Solutions to (a) and (b) are ultimate explanations, answering questions about why an organism possesses the trait, but (a) and (b) are discrete explanations, as the former provides the evolutionary history of the behavioral trait across species, while the latter indicates the function of the trait within a certain population. Solutions to (c) and (d) are proximate explanations; they answer questions about how the trait develops and operates in an individual. But (c) and (d) are distinct from one another, as the former addresses the question of how the trait develops during the lifecycle of the individual, and (d) addresses the question of how the trait operates. A comprehensive biological explanation of a behavioral trait, therefore, comprises four accounts, each stationed at a distinct explanatory level and each irreducible to the others. Another important feature of level analysis should be noted: competition among theories does not take place across the explanatory levels, but only within each level (Sherman 1988; MacDougall-Shackleton 2011). Each level of analysis is distinguished according to a unique explanandum, so none of the resulting explanantia making up the compound explanation is a rival to the others. 
Normative realism and level analysis

Returning now to the evolutionary explanation of evaluative judgment, if there were to be a competition between two rival explanations on, say, the grounds of ontological parsimony, it would have to occur at one or another explanatory level. This means that Street's point about ontological parsimony is relevant only if normative facts play a role for the realist at the same explanatory level as her account of evaluative judgment. But, if the realist adopts GCV, they would not. ALA is a functional consequence explanation; it seeks to answer an ultimate question about why evaluative judgments were selected for. GCV, the byproduct account I proposed, can also be characterized as a functional consequence account, though the functions it targets would be those for which the cognitive mechanisms underlying the capacity for evaluative judgment were selected. This means that at the level of functional consequences, normative facts do not factor into the picture for ALA and GCV. To see that this is the case, consider that GCV is committed to the view that grasping normative facts is not a biological function of these underlying mechanisms, but a byproduct of those mechanisms. Were we to exclude from the story any reference to a capacity for grasping normative facts, no substantive change to GCV would result. Thus, there does not seem to be any scenario in which ontological parsimony would directly impact our choice between ALA and GCV at the level of functional consequence.

Still, even if the realist adopts GCV, normative facts surely must figure into his/her biological account of true evaluative judgment, but if not at the functional consequence level, then where? Table 1 presents a simplified biological explanation of evaluative judgment the realist might offer. 
TABLE 1

\begin{tabular}{|l|l|}
\hline \multicolumn{1}{|c|}{ Ultimate Cause } & \multicolumn{1}{c|}{ Proximate Cause } \\
\hline \hline $\begin{array}{l}\text { a. Evolutionary history of enabling mechanisms } \\
\text { of grasping truth }\end{array}$ & $\begin{array}{l}\text { c. Normative facts + other genetic and } \\
\text { environmental factors }\end{array}$ \\
\hline $\begin{array}{l}\text { b. Function(s) of enabling mechanisms of } \\
\text { grasping truth }\end{array}$ & $\begin{array}{l}\text { d. Enabling mechanisms of grasping normative } \\
\text { facts and evaluative judgment making }\end{array}$ \\
\hline
\end{tabular}

As the table indicates, it makes most sense to place normative facts at the level of ontogeny. There are two reasons for this. First, independent normative facts are not elements for the construction of the phylogeny of the underlying components of evaluative judgment, particularly because on GCV, the capacity to grasp these facts did not come under selective pressure. And since the posited normative facts do not figure directly in a functional consequence account, the realist will not locate them at either of the two ultimate explanatory levels. This means, they should be located at one of the two proximate explanatory levels. Second, robust and nonreductive realists take normative facts to be independent of any attitude or stance. Normative facts, on their view, are grasped or tracked as features of our world independent of our evaluative attitudes, and realists understand normative facts as one factor in making evaluative judgments that are true. Of course, other relevant environmental factors, such as moral education, may have to be incorporated into the ontogenetic account of the development of evaluative judgment making and truth grasping in humans, but what is important for my purposes is that normative facts would not figure into either ultimate level of explanation, but at the ontogenetic level. This means that ALA, were it sound, would not enjoy prima facie superiority to GCV at the functional consequence level on grounds of ontological parsimony, because the latter does not require direct reference to independent normative facts. Any concern over ontological parsimony would take place at the level of ontogenetic factors affecting the making of evaluative judgment. To think 
that ontological parsimony matters in a direct comparison of GCV and ALA would be to blur the distinction between ultimate, functional explanation and proximate, ontogenetic explanation.

So how then does the realist justify the incorporation of irreducible normative truths into an ontogenetic explanation of our basic evaluative judgments? This is precisely where the antirealist should press his/her concern about ontological parsimony. Just as we would expect a defense of the particular details incorporated at any of the other explanatory levels, we should demand the normative realist show that the best ontogenetic explanation of evaluative judgment commits us to positing independent normative facts. But this matter will not be settled by an account of the phylogeny or functional consequence of evaluative judgment. Rather, that debate will center on whether we should countenance such facts at all, taking place on the usual epistemological, semantic, and ontological battlegrounds it traditionally has.

There are two main conclusions I wish to draw from this consideration of the levels of analysis. First, the worry that the normative realist's functional consequence account of evaluative judgment would violate a principle of ontological parsimony dissipates should the realist adopt GCV. In this case, the realist's functional consequence explanation need not involve direct reference to normative facts. Second, from a strictly evolutionary perspective, the question of whether there are independent normative facts appears underdetermined. Phylogenetic and functional consequence accounts of evaluative judgment do not point us toward or away from normative realism, and they offer little direct assistance in resolving this metaethical debate. By adopting GCV, therefore, the normative realist is not at a prima facie disadvantage to the antirealist from an evolutionary point of view. 


\section{Concluding remarks}

The strategy I provide in this paper is only one that the normative realist might deploy in countering DD. For Street's scientific challenge to pose a serious threat to normative realism, her Adaptive Link Account must be superior by the standards of scientific theory to any evolutionary explanation the realist can offer. But we have seen that Street's account faces serious theoretical difficulties and clearly falls short of the scientific standards to which she appeals in criticizing normative realism. We have also seen that there is a plausible evolutionary perspective on evaluative judgment that the realist can adopt, namely GCV. Finally, attention to the standard framework biologists utilize in explaining behavioral traits has shown that normative realism need not be at a prima facie theoretical disadvantage on grounds of ontological parsimony within the evolutionary debate, should the antirealist tender a plausible evolutionary account of evaluative judgment.

Normative realism continues to face serious philosophical challenges, and this paper does not provide anything approaching a full defense of the view. However, enough has been said to show that Street's scientific challenge can be met by the realist. Normative realism, therefore, is not faced with a peculiarly Darwinian dilemma.

\section{Acknowledgements}

I thank audiences at MIT, DePauw University, the University of Western Ontario, the University of Colorado Boulder, the University of Notre Dame, and the 2012 APA Eastern Division Meeting for helpful discussions of early versions of this paper. I am especially grateful to Robert Audi, Matthew Braddock, Justin Horn, Cailin O'Connor, Grant Ramsey, Benjamin Rossi, Christopher Shirreff, Kim Sterelny, Aleksy Tarasenko-Struc, Brandon Williams, and anonymous reviewers for valuable comments on drafts of this paper.

\section{References}

Atran, S. (2010). "The evolution of religion: How cognitive byproducts, adaptive learning heuristics, ritual displays, and group competition generate deep commitments to prosocial religions." Biological Theory 5(1): 18-30. 
Ayala, F. J. (2009). "The difference of being human: Morality." Proceedings of the National Academy of Sciences 107: 9015-9022.

Baker, A. (2007). "Occam's razor in science: A case study from biogeography." Biology and Philosophy 22: 193-215.

Barnard, A. (2012). Genesis of symbolic thought. Cambridge: Cambridge University Press.

Bartels, D. M. (2008). "Principled moral sentiment and the flexibility of moral judgment and decision making." Cognition 108: 381-417.

Bateson, P. \& Gluckman, P. (2011). Plasticity, robustness, development and evolution. Cambridge: Cambridge University Press.

Bickerton, D. (2009). Adam's tongue: How humans made language, how language made humans. New York: Hill and Wang.

Burian, R. M. (1983). “'Adaptation'.” In M. Greene (Ed.), Dimensions of Darwinism. Cambridge: Cambridge University Press.

Chapais, B. (2010). "The deep structure of human society: Primate origins and evolution." In P. M. Kappeler and J. B. Silk (Eds.), Mind the gap: Tracing the origins of human Universals (19-51). Heidelberg: Springer.

Cuneo, T. \& Shafer-Landau, R. (2014). "The moral fixed points: New directions for moral nonnaturalism." Philosophical Studies 171: 399-443.

De Jong, G. (1994). "The fitness of fitness concepts and the description of natural selection." Quarterly Review of Biology 69: 3-29.

De Lazari-Radek, K. \& Singer, P. (2014). The Point of View of the Universe: Sidgwick and Contemporary Ethics. Oxford: Oxford University Press.

De Smedt, J. \& De Cruz, H. (2010). "Toward an integrative approach of cognitive neuroscientific and evolutionary psychological studies of art." Evolutionary Psychology 8: 695-719.

Enoch, D. (2011). Taking morality seriously: A defense of robust realism. Oxford: Oxford University Press.

FitzPatrick, W. J. (2008). "Robust ethical realism, non-naturalism, and normativity.” In R. Shafer-Landau (Ed.), Oxford Studies in Metaethics, vol. 3 (pp. 159-206). Oxford: Oxford University Press.

--- (2015). "Debunking evolutionary debunking of ethical realism." Philosophical Studies 172: 883-904.

Fraser, B. J. (2014). "Evolutionary debunking arguments and the reliability of moral cognition." Philosophical Studies 168: 457-473.

Godfrey-Smith, P. (1996). Complexity and the function of mind in nature. Cambridge: Cambridge University Press.

Gould, S. J. (1991). "Exaptation: A crucial tool for evolutionary psychology.” Journal of Social Issues 47: 43-65.

Gould, S. J. \& Vrba, E. S. (1982). "Exaptation - a missing term in the science of form." Paleobiology 8: 4-15.

Hamlin, J. K. (2012). “A developmental perspective on the moral dyad." Psychological Inquiry 23:166-171.

Heiphetz, L. \& Liane Young (2014). "A social cognitive developmental perspective on moral judgment." Behaviour 151: 315-335.

James, S. M. (2011). An introduction to evolutionary ethics. Oxford: Wiley-Blackwell.

Joyce, R. (2006). The evolution of morality. Cambridge, MA: MIT Press. 
Kellert, S. H., Longino, H. E., \& Waters, C. K. (2006). "Introduction: The pluralist stance." In S. H. Kellert, H. E. Longino, \& C. K. Waters (Eds.), Scienftic pluralism (pp. vii-xxix). Minneapolis: University of Minnesota Press.

Kochanska, G. (2002). "Committed compliance, moral self, and internalization: A mediational model." Developmental Psychology 38(3): 339-351.

Kochanska, G. \& Murray, K. T. (2000). "Mother-child mutually responsive orientation and conscience development: From toddler to early school age." Child Development 71: 1424-1440.

Kochanska, G., D. R. Forman, N. Aksan, \& S. B. Dunbar (2005). "Pathways to conscience: Early mother-child mutually responsive orientation and children's moral emotion, conduct, and cognition." Journal of Child Psychology and Psychiatry 46(1): 19-34.

Kummer, H., Daston, L., Gigerenzer, G., \& Silk, J. (1997). "The social intelligence hypothesis." In P. Weingart, P. Richerson, S. D. Mitchell, \& S. Maasen (Eds.), Human by nature: Between biology and the social sciences (pp. 157-79). Hillsdale, NJ: Lawrence Erlbaum Associates.

Laible, D. (2007). "Attachment with parents and peers in late adolescence: Links with emotional competence and social paper." Personality and Individual Differences 43(5): 1185-1197.

Laible, D. \& Thompson, R. A. (2000). "Mother-child discourse, attachment security, shared positive affect, and early conscience development." Child Development 71(5): 14241440.

Laland, K. N. and Brown, G. (2011). Sense and nonsense: Evolutionary perspectives on human behavior. $2^{\text {nd }}$ edition. Oxford: Oxford University Press.

Lahti, D. C. (2003). "Parting with illusions in evolutionary ethics." Biology and Philosophy 18: $639-51$.

Lloyd, E. A. (2005). The case of the female orgasm: Bias in the science of evolution. Cambridge, MA: Harvard University Press.

MacDougall-Shackleton, S. A. (2011). "The levels of analysis revisited." Philosophical transactions of the Royal Society B 366: 2076-2085.

McGrath, S. (2014). "Relax? Don't do it! Why moral realism won't come cheap." In R. ShaferLandau (Ed.), Oxford Studies in Metaethics, vol. 9 (pp. 87-108). Oxford: Oxford University Press.

Miller, J. G. (1994). "Cultural diversity in the morality of caring: Individually oriented versus duty-based interpersonal moral codes." Cross-Cultural Research 28(1): 3-39.

Miller, J. G. \& Bersoff, D. M. (1992). "Culture and moral judgment: How are conflicts between justice and interpersonal responsibilities resolved?" Journal of Personality and Social Psychology 62(4): 541-554.

Nichols, S. (2002). "On the genealogy of norms: A case for the role of emotions in cultural evolution." Philosophy of science 69: 234-255.

Parr, L. \& F. B. M. De Waal (1999). "Visual kin recognition in chimpanzees." Nature 399: 647648.

Piattelli-Palmarini, M. (1989). "Evolution, selection and cognition: From 'learning' to parameter setting in biology and in the study of language." Cognition 31: 1-44.

Pinker, S. \& Bloom, P. (1992). "Natural language and natural selection.” In J. H. Barkow, L. Cosmides, \& J. Tooby (Eds.), The adapted mind: Evolutionary psychology and the generation of culture. Oxford: Oxford University Press.

Prinz, J. J. (2009). “Against moral nativism.” In D. Murphy \& M. Bishop (eds.), Stich and his 
critics (pp. 167-189). Oxford: Wiley-Blackwell.

Roeser, S. (2011). Moral emotions and intuitions. New York: Palgrave Macmillan.

Rosenberg, A. (1990). "The biological justification of ethics: A best-case scenario.” Social Philosophy and Policy 8: 86-101.

Ruse, M. (1986). "Evolutionary ethics: A phoenix arisen," Zygon 21: 95-112.

Shafer-Landau, R. (2003). Moral realism: A defense. Oxford: Oxford University Press.

Sherman, P. W. (1988). "Levels of analysis." Animal Behavior 36: 616-18.

Silk, J. B. (2003). "Cooperation without counting: The puzzle of friendship." In P. Hammerstein (Ed.), Genetic and cultural evolution of cooperation (pp. 37-54). Cambridge, MA: MIT Press.

--- (2005). “The evolution of cooperation in primate groups.” In H. Gintis, S. Bowles, R. Boyd, $\&$ E. Fehr (eds.), Moral sentiments and material interests: The foundations of cooperation in economic life. Cambridge: MIT Press.

Silk, J. B. and Boyd, R. (2010). "From grooming to giving blood: The origins of human altruism.” In P. M. Kappeler and J. B. Silk (Eds.), Mind the gap: Tracing the origins of human universals, (pp. 223-44). Heidelberg: Springer.

Sober, E. (1990). "Let's razor Ockham's razor." In Knowles, D. (Ed.), Explanation and its limits, Royal Institute of Philosophy supplementary volume 27 (pp. 73-93). Cambridge: Cambridge University Press.

Sterelny, K. (2003). Thought in a hostile world: The evolution of human cognition. Oxford: Blackwell.

--- (2012). The evolved apprentice: How evolution made humans unique. Cambridge, MA: MIT Press.

Stratton-Lake, P. (2002). “Introduction.” In P. Stratton-Lake (Ed.), Ethical intuitionism: Re-evaluations. Oxford: Oxford University Press.

Street, S. (2006). "A Darwinian dilemma for realist theories of value." Philosophical Studies 127:109-166.

Thompson, R. A., D. J. Laible, \& L. L. Ontai (2003). "Early understandings of emotion, morality, and self: Developing a working model." Advances in Child Development and Behavior 31: 137-171.

Tinbergen, N (1963). "On the aims and methods of ethology." Zeitschrift für Tierpsychologie 20: 410-33.

Vaish, A., Carpenter, M., and Tomasello, M. (2009). "Sympathy through affective perspective taking and its relation to prosocial behavior in toddlers." Developmental Psychology 45: 534-543.

--- (2010). "Young children selectively avoid helping people with harmful intentions." Child Development 81: 1661-1669.

Widdig, A. (2007). "Paternal kin discrimination: the evidence and likely mechanisms." Biological Reviews 82: 319-334. 